\title{
PENGARUH KUALITAS PELAYANAN, FASILITAS, PERSEPSI HARGA, DAN PROMOSI TERHADAP KEPUASAN KONSUMEN EXPRESS BAHARI DI KABUPATEN SUMENEP
}

\author{
Akhmad Edi Gunawan', Ahmad Ghufrony ${ }^{2}$ \\ ${ }^{1-2}$ Program Studi Manajemen, Universitas Wiraraja, Madura \\ 1edigunawan0086@gmail.com, ${ }^{2}$ ghufrony@wiraraja.ac.id
}

\begin{abstract}
Each cafe has its own advantages in the menu or Product Difersity (product diversity) and is supported by facilities aspects to make consumers feel satisfied. This research was conducted a case study at Jelata café, Lobuk Village, Bluto District. In answeringo these problems, the type fof research used is the quantitative method with 60 respondents who were taken. It is known that by this analysis, the sampling uses non-probability sampling methods and the data collection technique is incident sampling by distributing questionnaires. Thep data analysis techniqueaused is the reliability data validity test, classical assumption test, normality test and linearity test and heteroscedasticity test. From the research results, it shows the results of hypothesis testing that the significant value is (X1) $0.000<0.05$ and (X2) $0.016<0.05$. This means that H1 is acceptedsand HO is rejected, so itais said that there is a significantoinfluence on the dependentavariable so that it can besconcluded that Product Difference (X1) and wifi facilities (X2) have a partial effect on (Y) Jelata cafe consumer satisfaction.
\end{abstract}

Keywords : Product Diversity, wifi facilities, customer satisfaction

\begin{abstract}
ABSTRAK
Setiap café memiliki keunggulan masing-masing dalam menu atau Product Difersity (keragaman produk) serta ditunjang dengan aspek fasilitas untuk membuat konsumen merasa puas. Penelitian ini dilakukan studi kasus pada Jelata café Desa Lobuk Kecamatan Bluto. Dalama menjawab permasalahan tersebut, jenis spenelitian yang digunakan yaitu metode kuantitatif dengan responden yanga di ambil sebanyak 60 diketahui dengan analisis tersebut pengambilan sampela menggunakan metode non probability samplinga dan tekhnik pengambilan datanya sampling insidetaldengan cara penyebaran kuisoner. Adapun teknik analis data yanga digunakan yaitu uji validitas data areabilitas, uji asumsi klasik, uji normalitas dan uji linearitasa dan uji Heteroskedastisitas. Dari hasil penelitian menunjukkan hasil uji hipotesis bahwa nilai signifikan adalah sebesar (X1)a0,000<0,05 dan (X2)a0,016<0,05. Hal tersebut berarti H1 diterima dan H0 ditolak, maka dikatakan terdapat pengaruh signifikan terhadap variabel dependen sehingga dapat disimpulkan bahwaProduct Difersiti(X1) dan Fasilitas wifi (X2) terdapat pengaruh secara parsial terhadap (Y) kepuasan konsumen Jelata cafe.
\end{abstract}

Kata Kunci: Product Diversity, Fasilitas wifi, Kepuasan Konsumen

\section{PENDAHULUAN}

Hampir puluhan cafe yang tersebar. Dengan konsep yang berbeda beda. Keberagaman mengkbatkan para pengusha semakin berlomba untuk menarik konsomen sebanyak banyaknya. Dengan menerik kosumen dari berbagai kalangan, dari yang muda hingga yang tua dimana bisnis cafepun dapat dijadikan bisnis yang sangat menjanjikan.

Saat ini kota sumenep perkembangan bisnis cafe sangat marak beredar, dari yang sederhana hingga gaya modern, cafe yang ada di Sumenep sudah mulai banyak di dirikan, karena bisnis cafe sangat menjanjikan bagi para pengusaha. Akan tetapi dengan semakin banyaknya pendirian cafe di Kota Sumenep akan semakin banyak persaingan yang terjadi antar cafe dan antar pembisnis.

Jelata cafe adalah sebauah cafe yang didirikan oleh badan usaha milik desa yang memanfaatka aset Desa lobuk sebagai salah satu sumber pendapatan Desa, sebagai salah satu sumber pendapatan Desa, jelata cafe didirikan dengan sebaik mungkin dengan konsep sederhana agar para konsmen yang 
ada, bisa merasa nyaman ketika berada di jelata cafe.

Jelata cafe ialah satu satunya cafe yang ada di desa lobuk. Dimana cafe tersebut merupakan tempat para masyarakat dan pemuda Desa Lobuk berkumpul. di sertai dengan fasilitas dan produk yang ditawarka jelata cafe terhadap konsumen dapan menarik minat lebih banyak konsumen. Namun jelata cafe masih mempunyai beberapa masalah yang harus di perbaiki dan ditingkatkan terutama bagian menu yang ditawarkan atau keragaman produk(produc diversity). Karena jelata cafe tidak ada perubahan dalam menu baru yang ditawarkan hingga pengunjung kurang puas terhadap menu yang di tawarkan. Bukan hanya dari segi kergaman produk yang harus di perbaiki. Ada pula permasalahan kualias wifi yang masih kurang memadai dengan kecepatan wifi yang tidak bagus, sehingga para konsumen yang datang merasakan kurang puasan terhadap layanan yang ada di jelata cafe. Dari permasalahan yang telah di sebutka peneliti di atas, maka peneliti berinisiatif melakkan penelitian dengan sebuah judul “ Product Devircity Dan Fasiltas Wifi Terhadap Kepuasan Konsumen (Studi Kasus Pada Jeata Cafe Desa Lobuk Kecamatan Bluto Kabupaten Sumenep)"

\section{METODOLOGI PENELITIAN}

Jenis penelitian yang digunakan dalam penelitian ini adalah kuantitatif. Pada penelitian ini menggunakan studikasus dan lapangan merupakan penelitian dengan karateristik masalah yang berhubungan dengan latar belakang dan kondisi pada saat ini dari objek yang akan diteliti. alasan peneliti menggunakan penelitian kuantitatif karena peneliti ingin meneliti pengaruh Product Diversity dan Fasilitas wifi Terhadap Kepuasan Konsumen (Studi Kasus Pada Jelata Café Desa Lobuk Kecamatan Bluto). penelitian ini dilaksanakan pada bulan maret 2020.

$\begin{array}{rcrr}\text { Dalam } & \text { mengolah } & \text { data } & \text { peneliti } \\ \text { menggunakan } & \text { program } & \text { SPSS } & \text { untuk }\end{array}$ mengetahui pengaruh Product Diversity dan Fasilitas wifi sebagai variabel $\mathrm{X}$, terhadap kepuasan konsumen variabel Y. Teknik analisis data yang digunakan pada penelitian ini adalah uji validitas dan uji reabilitas, pada uji asumsi klasik peneliti hanya memfokuskan pada uji normalitas untum mengetahui data berdistribusi normal atau tidak agar dapat menentukan ketahap uji selanjutnya, dan selanjutnya pada uji hipotesis peneliti memfokuskan pada uj-t dengan menggunakan uji beda nonparametric 2 Related Sample.

\section{HASIL DAN PEMBAHASAN}

Uji ini untuk mengukur valid atau tidaknya data dari sebaran kuisioner yang berupa pernyataan yang telah disebar dan di isi olek konsumen Jelata Café Desa Lobuk Kecamatan Bluto. Data tersebut diolah menggunakan program SPSS.

Uji validitas digunakan untuk mengukur valid tidaknya suatu data kuisioner, uji Validitas ini untuk membandingkan besar $\mathrm{r}$ hitung dan $\mathrm{r}$ tabel dengan menggunakan correlation sehingga data menjadi valid, data yang dikatakan valid apabila besar $r$ hitung > r tabel. Hasil dapat Dilihat pada tabel dibawa ini:

Hasil Pengujian Uji Validitas (X1)

\begin{tabular}{|c|c|c|c|}
\hline Item & R Hitung & R Tabel & Keterangan \\
\hline $\mathrm{X} 1$ & 0.336 & 0.2542 & VALID \\
\hline $\mathrm{X} 2$ & 0.680 & 0.2542 & VALID \\
\hline $\mathrm{X} 3$ & 0.516 & 0.2542 & VALID \\
\hline $\mathrm{X} 4$ & 0.681 & 0.2542 & VALID \\
\hline
\end{tabular}

Sumber: data (spss 20) diolah 2020 


\section{Journal MISSY}

\section{(Management and Business Strategy)}

Vol. 1, Nomor. 2 November 2020

ISSN : 2775-3700

Hasil Pengujian Uji Validitas (X2)

\begin{tabular}{|c|r|c|c|}
\hline Item & R Hitung & R Tabel & Keterangan \\
\hline $\mathrm{X} 1$ & 0.438 & 0.2542 & VALID \\
\hline $\mathrm{X} 2$ & 0.524 & 0.2542 & VALID \\
\hline $\mathrm{X} 3$ & 0.506 & 0.2542 & VALID \\
\hline
\end{tabular}

Hasil Pengujian Uji Validitas (Y)

\begin{tabular}{|c|c|c|c|}
\hline Item & R Hitung & R Tabel & Keterangan \\
\hline Y1 & 0.658 & 0.2542 & VALID \\
\hline Y2 & 0.417 & 0.2542 & VALID \\
\hline Y3 & 0.522 & 0.2542 & VALID \\
\hline Y4 & 0.445 & 0.2542 & VALID \\
\hline
\end{tabular}

Dari hasil tabel di atas menunjukkan bahwa yang dikatakan valid apabila rhitung lebih besar dari r-tabel dari tabel di atas dapat disimpulkan bahwa semua item yang digunakan dinyatakan valid karena hasil rhitungcorrelation-item total correlation di atas > 0,2542 (r-tabel).

Uji reliabilitas digunakan untuk mengukur sejauh mana data tersebut bisa dipercaya dan konsisten dengan jawaban yang diberikan. Data tersebut dikatakan reliabel atau tidak reliabel dapat diketahui apabila hasil alpha croncbach's $>0,60$ karena penelitian ini di dapat menggunakan kuisioner.

Hasil Pengujian Uji Reliabilitas

\begin{tabular}{|c|c|c|c|}
\hline Variabel & $\begin{array}{c}\text { Cronbach's } \\
\text { Alpha }\end{array}$ & Batas Rebilitas & Keterangan \\
\hline $\begin{array}{c}\text { Product } \\
\text { Diversity (X1) }\end{array}$ & 0.749 & 0,60 & RERIABEL \\
\hline $\begin{array}{c}\text { Fasilitas wifi } \\
\text { (X2) }\end{array}$ & 0.672 & 0,60 & RERIABEL \\
\hline $\begin{array}{c}\text { Kepuasan } \\
\text { Konsumen (Y) }\end{array}$ & 0,717 & 0,60 & RERIABEL \\
\hline
\end{tabular}

Sumber: data ( spss 20) diolah 2020
Menunjukkan bahwa croncbach's alpha dari variabel product diversity (X1) yaitu hasil croncbach's alpha 0,749 yang artinya dia atas 0,60 jadi variabel product diversity dinyatakan reliable, variabel fasilitas wifi (X2) yaitu hasil croncbach's alpha 0,672 artinya diatas 0,60 juga dinyatakan reliable serta variabel $(\mathrm{Y})$ yaitu hasil croncbach's alpha 0,717 diatas 0,60 artinya dapat dinyatakan reliabel.

Uji normalitas dilakukan untuk mengetahui apakah variabel-variabel dalam penelitian ini berdistribusi normal atau tidak. Pengujian normalitas dapat dilihat dari output hasil dari spss yang menyatakan berdistribusi normal dapat dilihat dari hasil dibawah ini.

Hasil Pengujian Normalitas

One-Sample Kolmogorov-Smirnov Tes

\begin{tabular}{ll|r|}
\hline & & $\begin{array}{r}\text { Unstandardized } \\
\text { Residual }\end{array}$ \\
\hline N & Mean & 60 \\
Normal Parameters & Stb. & 1.37736754 \\
& Absolute & .152 \\
Most Extreme Differences & Positive & .060 \\
& Negative & -.152 \\
Kolmogorov-Smirnov Z & & 1.178 \\
Asymp. Sig. (2-tailed) & & .125 \\
a. Test distribution is Normal. & \\
b. Calculated from data. & \\
Sumber: output SPSS 2020 &
\end{tabular}

Penentuan yang dilakukan tersebut menunjukkan bahwa normalitas kolmogrov smirnov dengan tingkat signifikan variabelvariabel $=0,125>\alpha=0,05$ sehingga bisa dapat diketahui seluruh instrumen pernyataan penelitian tersebut bersifat normal.

Uji $\mathrm{T}$ digunakan untuk mengetahui secara pasti antara variabel-variabel independen dan variabel dependen apakah terjadi hubungan yang signifikan secara parsial dengan melihat tingkat signifikan yaitu 0,05 . Dengan asumsi apabila nilai probabilitas $>$ 0,05 maka H0 diterima dan H1 ditolak atau bisa dikatakan tidak terjadi pengaruh yang signifikan terhadap variabel dependen, dan 
sebaliknya apabila nilai probabilitas $<0,05$ maka H1 diterima dan $\mathrm{H} 0$ ditolak atau bisa dikatan terjadi pengaruh yang signifikan terhadap variabel dependen. Berikut adalah hasil dari uji parsial :

Hasil Uji Secara Parsial (Uji-T)

Coefficients ${ }^{*}$

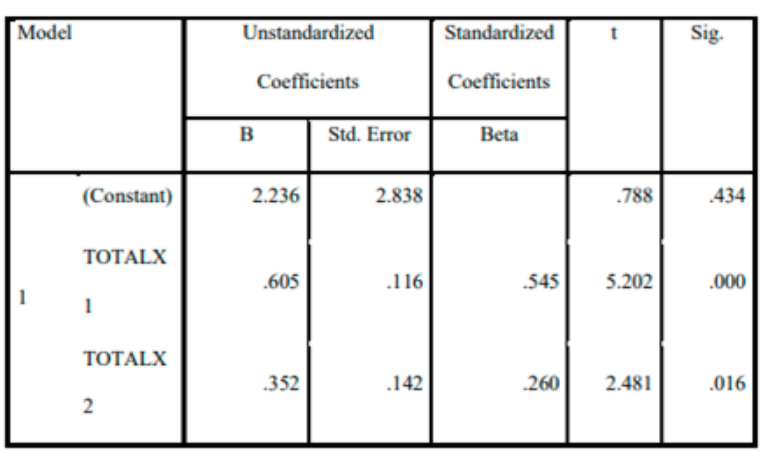

Pada tabel di atas diketahui bahwa nilai signifikan variabel product diversity (X1) adalah $0,000<0,05$ sehingga dapat disimpulkan bahwa product diversity (X1) terdapat pengaruh secara signifikan terhadap kepuasan konsumen (Y). Nilai signifikan variabel fasilitas wifi(X2) adalah $0,016<0,05$ sehingga dapat disimpulkan bahwa fasilitas (X2) terdapat pengaruh secara signifikan terhadap kepuasan konsumen $(\mathrm{Y}$

Uji simultan bertujuan untuk mengetahui apakah terdapat pengaruh secara bersama-sama (simultan) antara variabel independen terhadap variabel dependen dengan tingkat signifikan 0,05 . Jika nilai signifikannya $>0,05$ dan nilai $\mathrm{F}$ hitung $<$ dari F tabel maka dikatakan $\mathrm{H} 0$ diterima dan $\mathrm{H} 1$ ditolak dan sebaliknya.

Hasil Uji Secara Simultan (Uji - F) ANOvA*

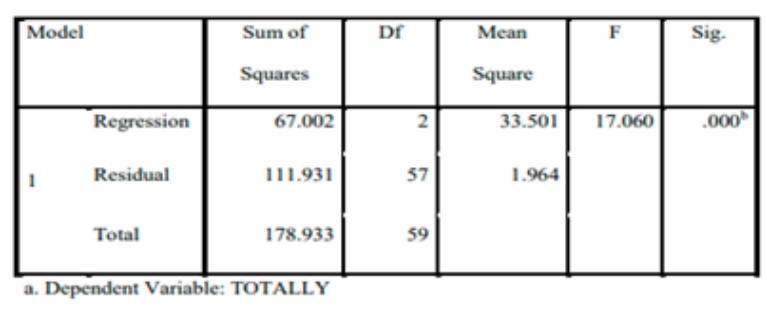

b. Predictors: (Constant), TOTALX2, TOTALX1

Sumber: output SPSS 2020
Pada tabel di atas diketahui bahwa nilai sig-f sebesar 0.000 . nilai ini lebih kecil dari alpa yang digunakan yaitu 0.05 . hal ini dapat disimpulkan bahwa Ho ditolak $\mathrm{H}_{1}$ diterima dengan artian terdapat pengaruh yang signifikan terhadap kepuasan konsumen dikarenakan nilai sig $<0,05$.

Hasil dari data diperlihatkan bahwa Product Diversity (X1) berpengaruh positif dan signifikan terhadap kepuasan konsumen (Y). Hal ini berarti bahwa Product Diversity berpengaruh terhadap kepuasan konsumen pada jelata cafe desa lobuk kecamatan bluto kabupaten sumenep. Penelitian ini sama dengan penelitian yang dilakukan oleh Inelsa Agustin, M. Nely Azhad da Budi Susanto (2019) menunjukkan bahwa Product Diversity berpengaruh pada kepuasan konsumen. dari pembahasan tersebut dapat disimpulkan bahwa semakin banyak Product Diversity yang diberikan oleh jelata cafe maka kupuasan konsumen semakin tinggi juga. Serta pada uji hipotesis juga menyebutkan bahwa terdapat pengaruh product diversity terhadap kepuasan konsumen.

Hasil dari data diperlihatkan bahwa kualitas fasilitas wifi (X2) berpengaruh positif dan signifikan terhadap kepuasan konsumen (Y). Hal ini berarti bahwa fasilitas wifi berpengaruh terhadap kepuasan konsumen pada konsumen jelata cafe. Penelitian ini sama dengan dengan pendapat Priyambodo (dalam Nawawi 2017:8) Menunjukkan bahwa fasilitas wifi berpengaruh secara signifikan pada kepuasan pelanggan. dari pembahasan tersebut dapat disimpulkan bahwa semakin lengkap dan nyaman fasilitas yang diberikan oleh Jelata cafe maka kupuasan konsumen semakin tinggi juga. Serta pada uji hipotesis juga menyebutkan bahwa terdapat pengaruh antara fasilitas wifi terhadap kepuasan konsumen. 
Product Diversity dan Fasilitas wifi sama-sama memiliki pengaruh terhadap kepuasan konsumen di Jelata cafe, akan teteapi dari kedua variabel tersebut ada yang lebih menonjol atau dominan berpengaruh dan bisa dilihat dari hasil uji linier berganda menunjukkan bahwa dintara dua variabel Product Diversity Fasilitas wifi () yang memiliki pengaruh terbesar terhadap Kepuasan konsumen(Y) adalah Product Diversity $\left(\mathrm{X}_{1}\right)$.

\section{KESIMPULAN}

penelitian yang telah dilakukan tentang pengaruh product diversity dan fasilitas wifi terhadap kepuasan konsumen maka dapat disimpulkan bahwa secara parsial produk diversity, fasilitas wifi berpengaruh dan signifikan terhadap kepuasan consume jelata cafe dikabupaten Sumenep. Dari hasil penelitian ini Secara simultanproduk diversiti dan fasilitas wifi terjadi pengaruh signifikan secara bersama-sama antar variabel.

\section{DAFTAR PUSTAKA}

Agustin Inelsa, Azhad M. Naely \& Santoso Budi. 2019. Product Diversity, Atmosfer Kafe dan Harga Dampaknya Terhadap Loyalitas Pelanggan Warung Kopi Cak Wang Banyuwangi. Jurnal Penelitian Ipteks.Vol4((1):63-78.

Arianti Nel. 2015. Pengaruh Kualitas Pelayanan dan Kualitas Produk Terhadap Kepuasan Konsumen Hanphone Samsung. Jurnal Ilmiah Manajemen dan Bisnis.Vol16(2)68-81

Fauzi Rizal Ula Ananata. 2017. Pengaruh Harga dan Free WI-FI Terhadap Keputusan Pembelian Produk Pada Angkringan Di Kecamatan Karas Kabupaten Magetan. Jurnal Aplikasi Bisnis.Vol.17(2):62-74.
Avitrain Hali Wiedyani, Rokh Eddy Prabowo. 2019. Pengaruh Kualitas Pelayanan, Persepsi Harga, dan Kepercayaan Terhadap Kepuasan Penumpang Kereta Api Argo Muria Jurusan Semarang Tawang-Jakarta Gambir. Prosiding Sendi.vol

Awy Apriani Ningrum Simamora dan Marlya Fatira AK. 2019. Kemudahan Aplikasi dan Keragaman Produk Dalam Membentuk Keputusan Pembelian Generasi Milenial Berbelanja Secara Onlen. Jurnal Maneksi. Vol (2):213-243

Fauzi Ananta Ula Rizal. 2017. Pengaruh Harga dan Free wifi Terhadap Kepuasan Pembelian Produk Pada Angkringan di Kecamatan Karas Kabupaten Magetan. Jurnal Aplikasi Bisnis. Vol.17(2):62-74

Manab Semarang, Sri Hartono, dan Burhanudin AY. 2019. Pengaruh Harga, Keragaman Produk dan Merek Terhadap Keputusan Pembelian Produk Pada PT. Index Sukoharjo. Edunomika vol.3(2):533-553

Nawawi. 2017. Persepsi Mahasiswa Menggunakan Fasilitas WIFI Dalam Mencari Informasi Dalam Kalangan Mahasiswa Fakultas Ilmu Sosial dan Ilmu Politik Universitas Riau. Jom Fisip.Vol.4(1):1-15

Rina Martiana, Sheli Aprianti. 2019. Pengaruh Kualitas Produk dan Kualitas Pelayanan Terhadap Kepuasan Konsumen Café Deumdee Rangkas Bitung.The Asia Pasific Journal of Managemen.Vol.6 (2):121134

Sari Novita, Setiowati Selfi. 2017. Pengaruh Keragaman Produk dan Kualitas Pelayanan Terhadap Kepuasan Konsumen Di PB Swalayan Metro. Jurnal Manajemen Magister. Vol.3.(2):186-199 
Sugiono, Jr. 2017. Metode Mpenelitian (3rded). Bandung: ALVABET CV.

Silvia, Fernando, Irasan Surya. 2019. Pengaruh Kualitas Pelayanan Dan Promosi Penjualan Terhadap Kepuasan Pelanggan Pada PT. Transpa Logistics (Perusahan Jasa Bergerak Di Kapal Lautan Trucking). Jurnal Aksara Public.vol.3(3):184-197

Syilvana Dwi Novianti. 2019. Influince Diversity of Products, Price, Promotion and Location Towards Costomer Satisfaction With Purchase Decision At Transmart Carrefour Plaza Medan Fair. Jurnal Axim. Vol.VIII(2):214-227

Umar Hi Sudirman, Parameswari Fahmi. 2019. Pengaruh Fasilitas Free wifi dan Charging Station Terhadap Kepuasan Penumpang Bandar Udara Internasional Supadio Pontianak. Jurnal Manajemen Dirgantara. Vol.12.(2):118-126

Yuwono Hendro, Yuwana Syamswana. 2017. Pengaruh Kualitas Pelayanan dan Keragaman Produk Terhadap Kepuasan konsumen Pada Toko King Di Malang. Jurnal Ekonomi Manajemen. Vol.2(1):331-346 